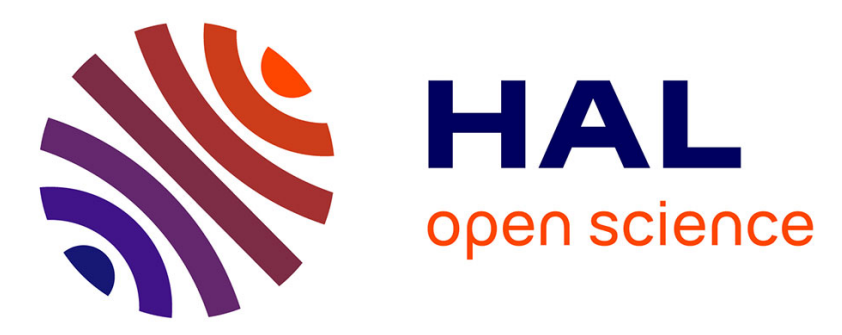

\title{
An experimental study of the effect of high-pressure water jet assisted turning (HPWJAT) on the surface integrity
}

\author{
Malek Habak, Jean-Lou Lebrun
}

\section{To cite this version:}

Malek Habak, Jean-Lou Lebrun. An experimental study of the effect of high-pressure water jet assisted turning (HPWJAT) on the surface integrity. International Journal of Machine Tools and Manufacture, 2011, 51 (9), pp.661-669. 10.1016/j.ijmachtools.2011.05.001 . hal-01067141

\section{HAL Id: hal-01067141 https://hal.science/hal-01067141}

Submitted on 23 Sep 2014

HAL is a multi-disciplinary open access archive for the deposit and dissemination of scientific research documents, whether they are published or not. The documents may come from teaching and research institutions in France or abroad, or from public or private research centers.
L'archive ouverte pluridisciplinaire HAL, est destinée au dépôt et à la diffusion de documents scientifiques de niveau recherche, publiés ou non, émanant des établissements d'enseignement et de recherche français ou étrangers, des laboratoires publics ou privés. 


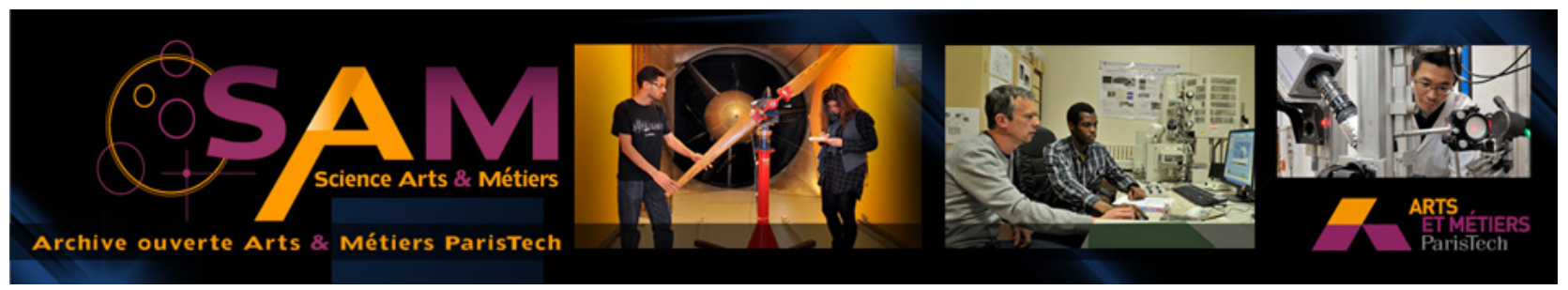

Science Arts \& Métiers (SAM)

is an open access repository that collects the work of Arts et Métiers ParisTech researchers and makes it freely available over the web where possible.

This is an author-deposited version published in: http://sam.ensam.eu

Handle ID: .http://hdl.handle.net/10985/8602

\section{To cite this version :}

Malek HABAK, Jean-Lou LEBRUN - An experimental study of the effect of high-pressure water jet assisted turning (HPWJAT) on the surface integrity - International Journal of Machine Tools and Manufacture - Vol. 51, n9, p.661-669 - 2011 


\title{
An experimental study of the effect of high-pressure water jet assisted turning (HPWJAT) on the surface integrity
}

\author{
Malek Habak $^{\mathrm{a}, \mathrm{b}, *}$, Jean Lou Lebrun ${ }^{\mathrm{b}}$ \\ a LTI-UPJV EA 3899, Avenue des Facultés, Le Bailly, Amiens Cedex 1, F-80001, France \\ ${ }^{\mathrm{b}}$ LPMI-EPPM-ENSAM/CER 02, Bd du Ronceray, BP 93525-49035 Angers Cedex 01, France
}

Keywords:

Austenitic stainless steel

Water jet assisted turning

High pressure

Chip shape and residual stresses

\begin{abstract}
A B S T R A C T
This study deals with the effect of High-Pressure Water Jet Assisted Turning (HPWJAT) of austenitic stainless steels on chip shape and residual stresses. The machining of the austenitic stainless steels represents several difficulties. Recently, research has shown that the introduction of a high-pressure water jet into the gap between the tool and the chip interface is a very satisfactory method for machining applications. In this article, the effect of a high-pressure water jet, directed into the toolchip interface, on chip shapes breakage and surface integrity in face turning operations of AISI 316L steel has been investigated. Tests have been carried out with a standard cutting tool. The cutting speeds used were 80 and $150 \mathrm{~m} / \mathrm{min}$, with a constant feed rate of $0.1 \mathrm{~mm} / \mathrm{rev}$ and a constant cutting depth of $1 \mathrm{~mm}$. Three jet pressures were used: 20, 50 and $80 \mathrm{MPa}$. Residual stress profiles have been analysed using the X-ray diffraction method in both longitudinal and transversal directions. The results show that jet pressure and cutting parameters influence the residual stresses and the chip shapes. Using a high-pressure jet, it is possible to create a well fragmented chip in contrast to the continuous chip formed using dry turning. It is also possible to control the chip shape and increase tool life. When the jet pressure is increased the residual stress at the surface decreases; however it is increased by an increase in cutting speed. It can be concluded that surface residual stresses can be reduced by the introduction of a high-pressure water jet.
\end{abstract}

\section{Contents}

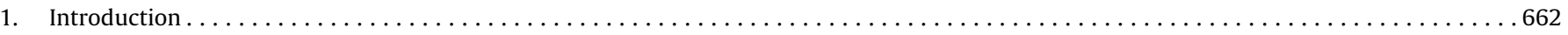

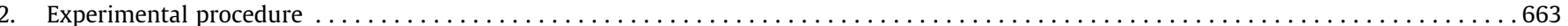

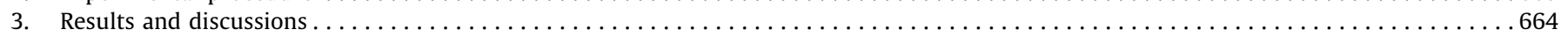

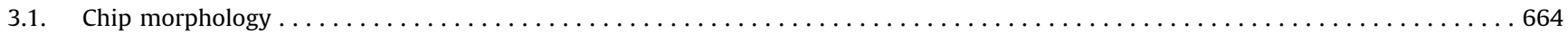

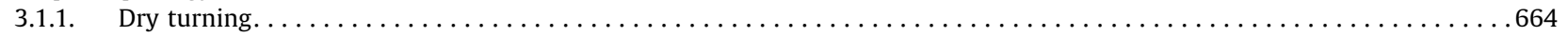

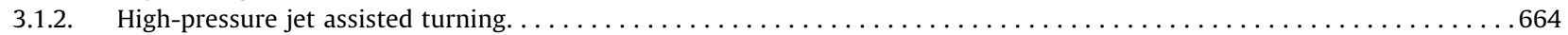

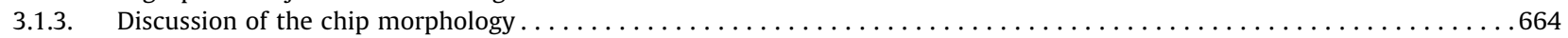

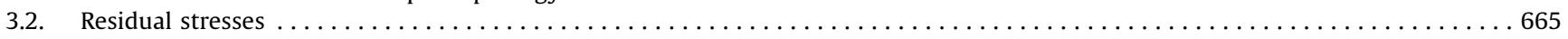

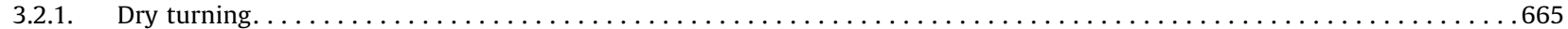

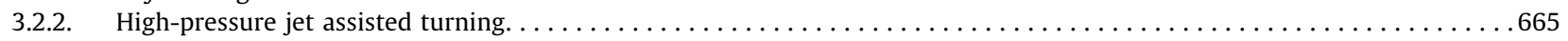

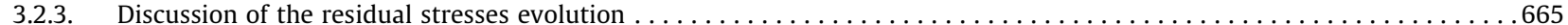

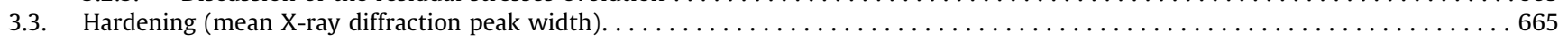

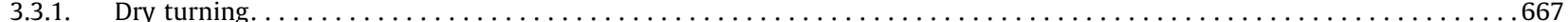

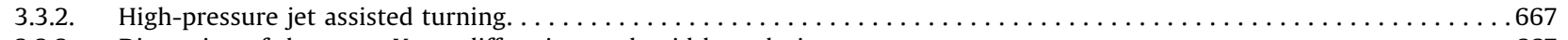

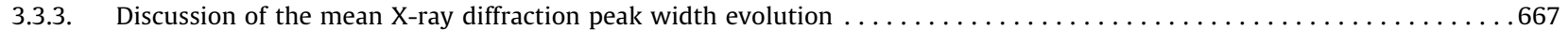

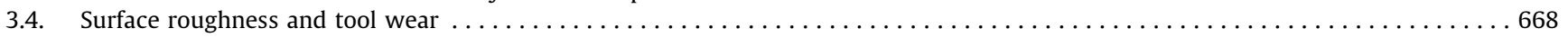

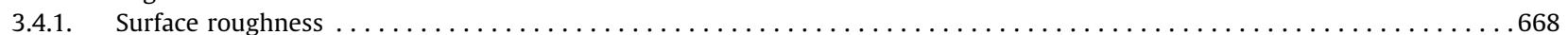

\footnotetext{
* Corresponding author at: LTI-UPJV EA 3899, Avenue des Facultés, Le Bailly, Amiens Cedex 1, F-80001, France. Tel.: +33 322534035 ; fax: + 3322956889.

E-mail address: malek.habak@u-picardie.fr (M. Habak).
} 


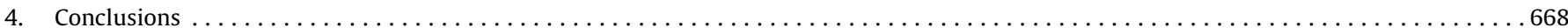

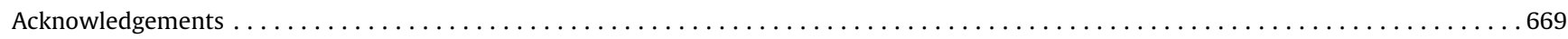

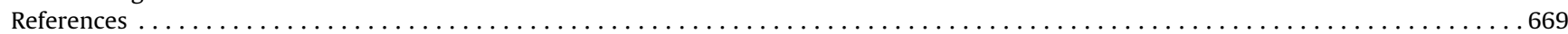

\section{Introduction}

Machining of austenitic stainless steels is considered to be difficult. The high plastic deformations introduced by turning generate large amounts of heat in the cutting zone, which can modify the characteristics of the tool and machined material [1-6]. Turning introduces on the surface of the workpiece a residual stress gradient that is critical for the components life, its fatigue behaviour, and corrosion resistance. The residual stress profile is the result of mechanical, thermal and metallurgical effects, which are governed by the cutting parameters, the characteristics of the workpiece and the tool. In turning, the generation mechanisms of the residual stresses are very complex and generally result from a coupling between thermal, mechanical and metallurgical effects intervening in the cutting zone during the generation of the chips [7-13]. It is thus necessary to know the gradient of residual stresses after machining. The study of these gradients makes it possible to characterize the surface integrity.

M'Saoubi et al. [1] examined the effect on residual stresses induced by dry orthogonal turning of AISI 316L steels for different cutting conditions, tool geometries and tool coatings. They conclude that for all tests, at the extreme surface of the workpiece, machining produces a high tensile stress, associated with a high degree of hardening. They showed that tension affected by tensile stress decreases with cutting speed, but increases for high feed rate values. In 2005, Capello [2] presented a relationship between the turning parameters and the residual stresses. In his contributions, the effects of feed rate and tool nose radius were reported to have an influence on residual stresses in the workpiece surface. His work's is interesting in the sense that it proposes a simple regression model, which can be used in the selection of the process parameter that will generate the desired residual stress state. Similarly, Rech and Moisan [3] studied the influence of feed rate, cutting speed and tool wear on the surface integrity induced by hard turning of $27 \mathrm{MnCr} 5$ steels. They concluded that the cutting speed is the dominant factor that influences the residual stress level. These results were also showed by Jacobson et al. [4] and Dahlman et al. [5] for hard turning of bainite steels. The existence of a white layer in hard turning and its relation to surface residual stresses was found by Schwach and Guo [6]; they determined the feasibility of producing distinct type of surface integrity by the process design (turning of AISI 52100 with a hardness of $61 \mathrm{HRc}$ ). These pioneering studies help us identify the surface integrity created by hard turning; operations favourable surface integrity for improving fatigue life can be produced using small feeds and sharp cutting tools. Decreasing the feed makes surface residual stress more compressive and the maximum compressive residual stresses shallower in the subsurface. A white layer is primarily associated with tensile surface residual stresses.
Austenitic stainless steels find extensive applications, thanks to their excellent physical and metallurgical properties. Unfortunately these same properties result in relatively poor machinability. Hence the machining of these materials requires the use of new processes that make it possible to break chips to improve the tool life and the quality of surface machining. High-Pressure Water Jet Assisted Turning (HPWJAT) is one of the main methods used for these purposes. Some studies have shown that the application of a high-pressure water jet to the tool-chip interface leads to control of the chip shapes $[14,15]$. With this process, it is a question of not only lubricating the cutting zone but also directing a high-pressure water jet between the tool and the chip to create a hydraulic corner. This improves chip breakage, increases tool life and improves the machined surface quality. Dahlman and Escursell [15] conclude that the use of ultra-high pressure cooling improved significantly the chip control compared to dry machining, especially when wiper insert geometry is used. Also, they observed that the surface roughness value (surface topography) seems to decrease by about $80 \%$ when ultra-high pressure cooling is retained.

Avila and Abrao [16] studied tool life, surface finish, tool wear mechanisms and chip shapes obtained in turning of AISI 4340 steel (49 HRC) using different cutting fluids. Viera et al. [17] examined tool life, power consumption and surface roughness during face milling. They concluded that dry machining produces a slightly better finish surface than machining using a cutting fluid ad that the cutting fluids reduce the tool-chip interface temperature compared to dry cutting. According to [16], the use of a cutting fluid based on an emulsion without mineral oil results in longer tool life compared to dry cutting. When finish cutting at high cutting speeds, the use of cutting fluid is responsible for reducing the scatter in surface roughness values. Kovacevic et al. [18] have explored the influence of a high-pressure water jet delivered to tool-chip interface in two different ways: (1) water jet injected directly into the tool-chip interface through a hole in the tool rake face and (2) water jet injected into the tool-chip interface through an external nozzle. They observed a drastic reduction in the cutting forces required to remove material from the workpiece when a high-pressure water jet is used. Also, the surface finish obtained for both methods of jet application was much better than that obtained using flood cooling. For the case where the high-pressure water jet was delivered through an external nozzle, the tool-chip contact area is reduced by the fragmentation of the chip. The decrease in cutting force is accompanied by an improvement in tool life, surface finish and chip shape. Hence, the use of a high-pressure water jet as a coolant/lubricant leads to an improvement in the metal removal rate and consequently improves the efficiency of rotary tool operations, especially in the case of difficult-to-machine materials. The effects of high and ultra-high pressure water jets directed into the tool-chip interface on tool temperature, cutting forces,

Table 1

Chemical analysis of AISI 316L (steel used for this work).

\begin{tabular}{|c|c|c|c|c|c|c|c|c|c|c|c|c|c|c|}
\hline \multicolumn{15}{|c|}{ Chemical composition of 316L material (wt\%) } \\
\hline $\mathrm{C}$ & $\mathrm{Si}$ & Mn & $\mathrm{Ni}$ & $\mathrm{Cr}$ & Mo & $S$ & $\mathrm{P}$ & $\mathrm{Nb}$ & Co & $\mathrm{Cu}$ & V & Sn & $\mathrm{Ti}$ & $\mathrm{Fe}$ \\
\hline 0.031 & 0.509 & 1.764 & 10.561 & 17.493 & 2.107 & 0.024 & 0.026 & 0.042 & 0.114 & 0.433 & 0.084 & 0.021 & 0.009 & Balance \\
\hline
\end{tabular}


chip shape and surface roughness have been explored by Kaminski and Alvelid [19] in regular turning operations. The results show a significant reduction in the edge temperature of about $40 \pm 45 \%$. This author concluded that the water jet can be used to obtain good heat dissipation, to control the chip forming process and finally to change the cutting process by changing the frictional conditions and thus the shear plane angle. The simulation of high-pressure water jet assisted orthogonal metal cutting has been carried out by Shet et al. [20]. In this study, water is injected directly into the tool-chip interface through a small hole on the rake face of the tool. Simulation shows a fall in temperature, cutting force and residual stresses for water jet assisted cutting conditions.

Indeed, in spite of a great number of studies relating to machining, little of them treats high-pressure water jet assisted turning methods and their effect on residual stresses. In this study, the effect of high-pressure water jet assisted turning (HPWJAT) on residual stresses is investigated and the analysis of the physical mechanisms intervening in the generation of the chip and on the surface of machined workpiece is carried out.

\section{Experimental procedure}

Face turning experiments were conducted on a numerically controlled lathe (RAMO RACN20). Cylinders of austenitic stainless steel (AISI 316L) with a diameter of $110 \mathrm{~mm}$ were selected for the study. The chemical composition of this material is presented in Table 1.

Machining tests were conducted at 80 and $150 \mathrm{~m} / \mathrm{min}$ cutting speeds, at a constant feed rate of $0.1 \mathrm{~mm} / \mathrm{rev}$ and with a constant cutting depth of $1 \mathrm{~mm}$. Experiments were carried out under dry turning conditions and with high-pressure jet assisted turning (HPWJAT). The jet was composed of $95 \%$ of water and $5 \%$ of soluble oil. Three jet pressures were used: 20,50 and $80 \mathrm{MPa}$. An external high-pressure pump was used to provide high jet pressure (jet flow $=6.6 \mathrm{l} / \mathrm{min}$ ). A standard orifice of $0.6 \mathrm{~mm}$ in diameter was fixed on the tool holder. The jet was directed into the tool-chip interface as shown in Fig. 1.

The use of high-pressure water jet in the lathe imposes an additional protection of the doors, the slides and the pin. Against the water and chips infiltrations, the protection of the slides, the longitudinal and the transversal carriages were reinforced by the installation of bellows and stainless sheet scales. The bellows allow easy drainage of water and chips. Concerning the exhaust of the oil and water vapours, a rubber gasket was stuck to the lathe doors. To protect the pin and the bearings to the high-pressure aggressions, housing was set up making it possible to limit the water infiltrations without obstruction for the movement and disassembling of the chuck, the workpiece and the accessibility for various workpiece diameters.

The high-pressure water jet is powerful enough to be rectilinear to the cutting tool. The positioning of the jet impact point is carried out by rotation of the orifice fixed on the tool holder

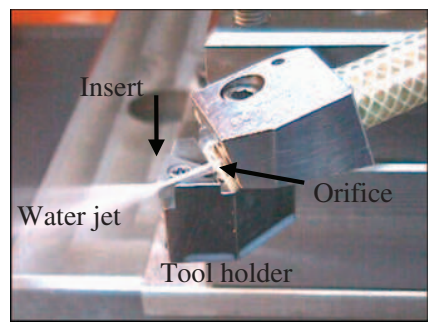

Fig. 1. Principle of high-pressure jet assisted turning.
(Fig. 1) and wedges height adjustment (compared to the tool reference plan). The orifice fixation is assured by a screw.

To determine the jet position, several impact points were studied. Tests were carried out to understand their effect, in turning, on the chips fragmentation and their evacuation. Three impact points were studied. The result showed that displacement of some millimetres changed considerably the chips shape and influenced the tool degradation. These tests were carried out at a cutting speed of $80 \mathrm{~m} / \mathrm{min}$, a feed rate of $0.3 \mathrm{~mm} / \mathrm{rev}$ and a jet pressure of $100 \mathrm{MPa}$. It was observed that

1. Directing high-pressure water jet on the chip gives a disappointing result. A premature rupture of the cutting tool is observed and the chips obtained were not fragmented.

2. If the water jet is directed on the workpiece, it was noted that this configuration causes, by erosion, a degradation of machined surface, which generates a poor surface quality. The surface roughness to be increased by more than $50 \%$, compared to the case where the jet is directed on the chip. It was concluded that it is necessary to limit the direct contacts of the high-pressure jet on the workpiece to avoid this degradation. Also, in this case the chip is not fragmented, and does not allow avoiding the phenomenon of adherent chip. However, this orientation makes it possible to evacuate the chips (no chip impact on the surface workpiece).

3. The chips were perfectly fragmented; the tool wear decrease and a good surface roughness are obtained when the highpressure jet is directed into the tool-chip interface. The cutting tool was well preserved and without the presence of adherent chip. This configuration gives satisfaction and it was retained for our study.

An uncoated carbide grade tool insert was chosen for all tests. The insert reference is TCMW16T304 H13A from Sandvik. This tool is not specifically meant for the machining of austenitic stainless steels. The objective is to obtain a bad machining, which produces long chips and then to find a solution to fragment it using high pressure jet assistance.

During the experiments, all chips were collected, polished and etched with a Fry4 solution to observe the microstructure using an optical microscope and a scanning electronic microscope. Comparison in terms of their shape has been made.

Residual stresses and work hardening, which depend on the cutting speed and jet pressure, were investigated. The residual stress profile and mean X-ray diffraction peak width profile have been analysed using a portable X-ray diffractometer from Proto$\mathrm{XRD}$, and successively removing the surface layer of the workpiece by electropolishing. The depth error measurement is $10-20 \mu \mathrm{m}$.

The stresses were analysed in longitudinal $\sigma_{x x}$ and transversal directions $\sigma_{y y}$ (see Fig. 2). The parameters used to measure the stresses are given in Table 2.

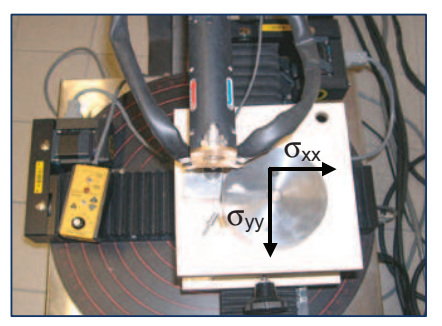

Fig. 2. Residual stresses were analysed by X-ray diffraction in the $\sigma_{x x}$ and $\sigma_{y y}$ directions. 
Table 2

Parameters used for the X-ray analysis.

\begin{tabular}{|c|c|c|c|c|c|c|c|}
\hline Test material & Collimator (mm) & Tension (kV) & $(\mathrm{mA})$ & Wavelength (nm) & Radiation & Bragg angle, $2 \theta$ (deg.) & $h k l$ \\
\hline Fe $\gamma$ & 2 & 20 & 4 & 0.210 & $\mathrm{Mn} \_\mathrm{K}_{\alpha}$ & 152.3 & 311 \\
\hline
\end{tabular}
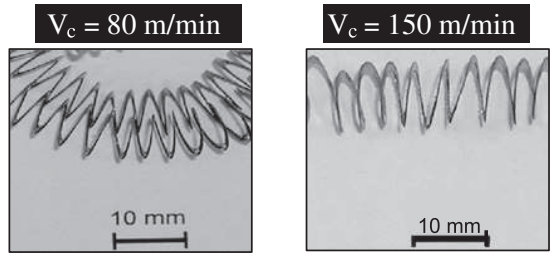

Fig. 3. Chip shapes obtained by dry turning at $a_{\mathrm{p}}=1 \mathrm{~mm}$ and $f=0.1 \mathrm{~mm} / \mathrm{rev}$.
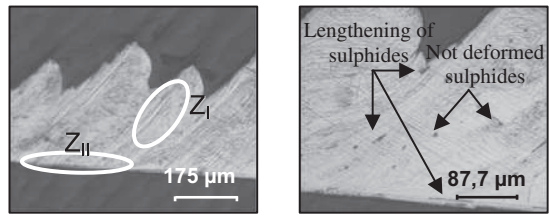

Fig. 4. Chip microstructures obtained in dry turning at $V_{\mathrm{c}}=150 \mathrm{~m} / \mathrm{min}, a_{\mathrm{p}}=1 \mathrm{~mm}$ and $f=0.1 \mathrm{~mm} / \mathrm{rev}$.

The X-ray source is a $\mathrm{Mn}$ anode. The residual stress is calculated by

$2 \theta=f\left(\sin ^{2} \psi\right)$

To study the variations in the distance between atomic layers $\left(d_{h k l}\right)$, which is indicative of the elastic strain of the crystal, we chose the family of atomic planes $\left\{\begin{array}{ll}3 & 1 \\ 1\end{array}\right\}$ in $(\gamma)$ iron. The elasticity constants taken are $1 / 2 S_{2}=6.531 \times 10^{-6} \mathrm{MPa}^{-1}$ and $S_{1}=$ $-1.429 \times 10^{-6} \mathrm{MPa}^{-1}$. Acquisition is done with two detectors ( $\omega$ fitting) the angles returned are in $\beta$ for acquisition durations of $20 \mathrm{~s}$ for each $\beta(-30>\beta>30)$.

\section{Results and discussions}

\subsection{Chip morphology}

\subsubsection{Dry turning}

The different chip shapes obtained in dry turning for the different test conditions are presented in Fig. 3. It can be concluded that using dry turning, chips were not broken at cutting speeds of 80 and $150 \mathrm{~m} / \mathrm{min}$.

Fig. 4 shows the typical chip microstructure obtained for cutting speed of $V_{c}=150 \mathrm{~m} / \mathrm{min}$ and feed rate of $f=0.1 \mathrm{~mm} / \mathrm{rev}$ by dry turning.

\subsubsection{High-pressure jet assisted turning}

An example of different chip shapes obtained in HPWJAT for the different test conditions $\left(V_{\mathrm{c}}=150 \mathrm{~m} / \mathrm{min}, f=0.1 \mathrm{~mm} / \mathrm{rev}, a_{\mathrm{p}}=1 \mathrm{~mm}\right.$ and jet pressure $P=50$ and $80 \mathrm{MPa}$ ) are presented in Fig. 5. It was noted that jet pressure has a strong influence on chip geometry.

Fig. 6 shows an example of the chip microstructure obtained using HPWJAT for cutting speed $V_{\mathrm{c}}=150 \mathrm{~m} / \mathrm{min}, a_{\mathrm{p}}=1 \mathrm{~mm}$ and feed rate of $f=0.1 \mathrm{~mm} / \mathrm{rev}$ at jet pressure values of $50 \mathrm{MPa}$.

\subsubsection{Discussion of the chip morphology}

It is observed that when using dry turning, the chips were curled and not broken (Fig. 3). The austenitic stainless steel tends to harden during the cutting to form a long chip.
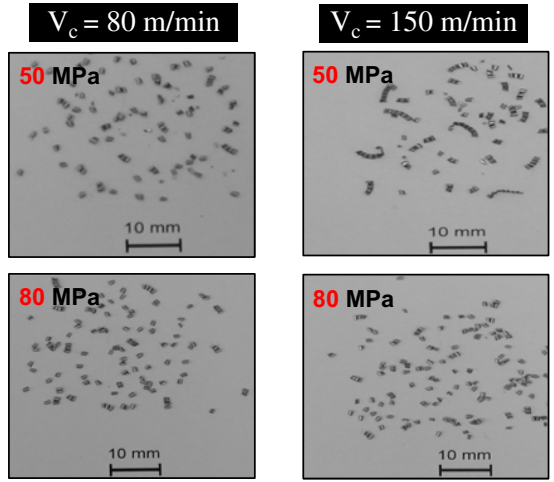

Fig. 5. Chip shapes obtained by HPWJAT at $a_{\mathrm{p}}=1 \mathrm{~mm}$ and $f=0.1 \mathrm{~mm} / \mathrm{rev}$.

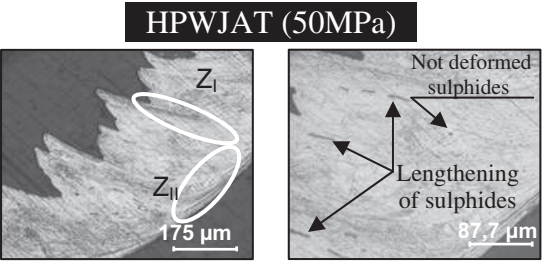

Fig. 6. Chip microstructures obtained by HPWJAT at $V_{\mathrm{c}}=150 \mathrm{~m} / \mathrm{min}, a_{\mathrm{p}}=1 \mathrm{~mm}$ and $f=0.1 \mathrm{~mm} / \mathrm{rev}$.

With the same parameters in HPWJAT, good chip control was provided (Fig. 5). When cutting speed was increased, only a slight elongation of chips was observed. It was seen that the introduction of a high-pressure water jet into the interface between the tool and the chip makes it possible to break the chips into the desired shape and to evacuate the chips without altering the workpiece surface.

Comparing to the chip microstructure obtained in dry turning (Fig. 4), the chip microstructure presented in Fig. 6 shows intense shearing action in the case of HPWJAT and that the sulphide particles were very deformed in the primary $\left(\mathrm{Z}_{\mathrm{I}}\right)$ and secondary $\left(Z_{\text {II }}\right)$ shearing zones. This deformation can be explained by the action of the pressure exerted by the tool on the surface workpiece during the machining operation and it is depending to the material and the cutting conditions. During machining, the tool comes into contact with the workpiece surface and the progression of the tool causes a strong compression of the workpiece material and generates an intense shearing between the point of the tool and the surface of the workpiece. This gives rise to primary $Z_{I}$ shearing zone. In the friction zone between the tool and the chip, the chip undergoes a rolling, combined with a shearing, which creates a secondary $Z_{\text {II }}$ shearing zone. The deformations generated by these shearing actions can cause a lengthening of the grains and the deformation of sulphides and inclusions in zones $\mathrm{Z}_{\mathrm{I}}$ and $\mathrm{Z}_{\mathrm{II}}$.

The chip microstructure (presented in Figs. 4 and 6) shows an intense shearing indicated by the big serrations. As observed by scanning electron microscope (see Fig. 7), comparing the dry turning (Fig. 7a) and the HPWJAT (Fig. 7b), for the same parameters, the primary shear zones were very pronounced in HPWJAT, which explains the chip fragmentation in this case. 
When the high-pressure jet is applied, friction is reduced at the tool-chip interface due to the formation of a cushioning layer, which prevents close contact at the tool-chip interface, and consequently leads to the bending and the breakage of the chips. These experimental results highlight the advantages of the HPWJAT in terms of chip fragmentation.

\subsection{Residual stresses}

In this section, residual stress profiles within the depth of the workpiece are plotted for HPWJAT and dry turning for different cutting conditions. The stresses obtained were shifted by about $6 \mu \mathrm{m}$ to correspond to the X-ray penetration on the material. As shown in Fig. 8, the residual stress profiles can be divided into two regions: the region closest to the surface of the workpiece $\left(A_{1}\right)$ being affected by tensile stresses and to the compressive part.

\subsubsection{Dry turning}

Fig. 8 shows different depth profiles obtained in the case of dry turning. In each case, the same evolution between longitudinal $\sigma_{x x}$ and transversal $\sigma_{y y}$ stresses can be observed. All the residual stress distributions have the same evolution. Hence, the longitudinal stress profiles are not discussed in the following. The maximum stress is located at the surface of the workpiece. The maximum value of longitudinal residual stress ranges from $+760 \mathrm{MPa}$ (tension) to $-180 \mathrm{MPa}$ (compression) for a cutting speed of $V_{\mathrm{c}}=150 \mathrm{~m} / \mathrm{min}$, a feed rate of $f=0.1 \mathrm{~mm} / \mathrm{rev}$ and a cutting depth of $a_{\mathrm{p}}=1 \mathrm{~mm}$.

\subsubsection{High-pressure jet assisted turning}

As shown for dry turning, the same evolution between longitudinal $\sigma_{x x}$ and transversal $\sigma_{y y}$ stresses (see Fig. 9) can be observed. When using the high-pressure jet the surface residual stress $\left(\sigma_{x x}\right)$ ranges from $+460 \mathrm{MPa}$ (tension) to $-180 \mathrm{MPa}$

a

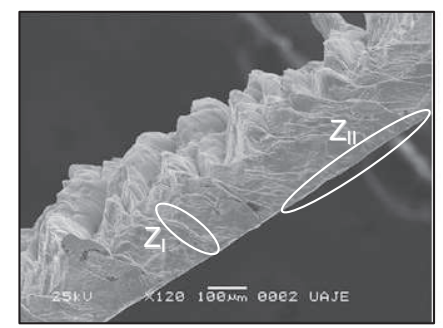

b

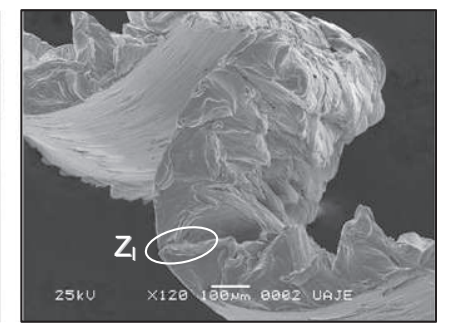

Fig. 7. SEM views of the chip shapes obtained by dry turning and HPWJAT at $V_{\mathrm{c}}=150 \mathrm{~m} / \mathrm{min}, a_{\mathrm{p}}=1 \mathrm{~mm}$ and $f=0.1 \mathrm{~mm} / \mathrm{rev}$ : (a) dry turning and (b) HPWJAT $(P=50 \mathrm{MPa})$. (compression) for a cutting speed of $V_{\mathrm{c}}=80 \mathrm{~m} / \mathrm{min}$ and from +600 to $-180 \mathrm{MPa}$ for a cutting speed of $V_{\mathrm{c}}=150 \mathrm{~m} / \mathrm{min}$ (Fig. 9).

\subsubsection{Discussion of the residual stresses evolution}

As presented previously, for all cases, the same evolution between longitudinal $\sigma_{x x}$ and transversal $\sigma_{y y}$ stresses can be observed. Hence, the transversal stress profiles are not discussed in the following.

On the machined surface, tensile stress fields were obtained for each condition investigated. This has also been observed in $[1,10,21]$. This is essentially attributed to the thermal gradient, the mechanical effects and the high deformation introduced during the turning operation.

The sensitivity of the residual stress to the jet pressure is very pronounced (Fig. 10). On the surface, the tensile stresses decrease when the jet pressure is increased. The surface residual stress $(+460 \mathrm{MPa})$ obtained using HPWJAT at $V_{\mathrm{c}}=80 \mathrm{~m} / \mathrm{min}$ with a jet pressure of $P=20 \mathrm{MPa}$ is much higher compared to the values obtained $(+220 \mathrm{MPa})$ using HPWJAT at $V_{\mathrm{c}}=80 \mathrm{~m} / \mathrm{min}$ with a jet pressure of $P=80 \mathrm{MPa}$. An average change of approximately 100-200 MPa was observed. These results can be explained by the temperature reduction due to the use of the jet. The pressure exerted by the jet on the chip face reduces friction along the toolchip interface.

The study of the effect of cutting speed has been carried out for two cutting speed values ( 80 and $150 \mathrm{~m} / \mathrm{min}$ ) and for different jet pressures (20, 50 and $80 \mathrm{MPa}$ ). The results obtained are presented in Table 3. It is shown that when the cutting speed is increased from 80 to $150 \mathrm{~m} / \mathrm{min}$ the surface longitudinal residual stress increases by approximately $200-250 \mathrm{MPa}$ in dry turning as well as in HPWJAT.

When the cutting speed increases, the heat gradient introduced by the process becomes more significant, which has a tendency to produce tensile stresses at the surface. The influence of cutting speed can also be explained by the chip flow speed in the cutting zone, which increases with greater cutting speed and leads to grater heat evacuation. These results are in agreement with those obtained in [9] for the orthogonal machining of AISI 304 steels and by Capello [2] for the orthogonal turning of AISI 316L steels. Thus, it seems that the cutting speed and the use of high-pressure water jet do not have a great influence on the depth of the residual stress zone affected by tension $\left(A_{1}\right)$, which varies between 20 and $50 \mu \mathrm{m}$ (see Table 3).

\subsection{Hardening (mean X-ray diffraction peak width)}

The work hardening is analysed using the X-ray diffraction method. The evolution of mean X-ray diffraction peak width determines the hardening level and the depth affected by

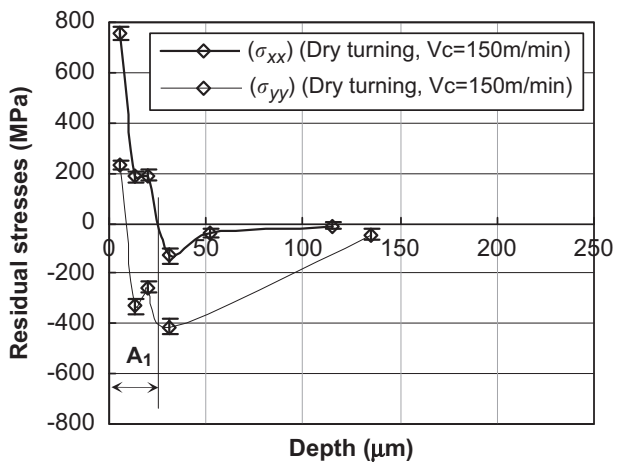

Fig. 8. Longitudinal and transversal residual stress profiles obtained in dry turning $\left(f=0.1 \mathrm{~mm} / \mathrm{rev}\right.$ and $\left.a_{\mathrm{p}}=1 \mathrm{~mm}\right)$. 

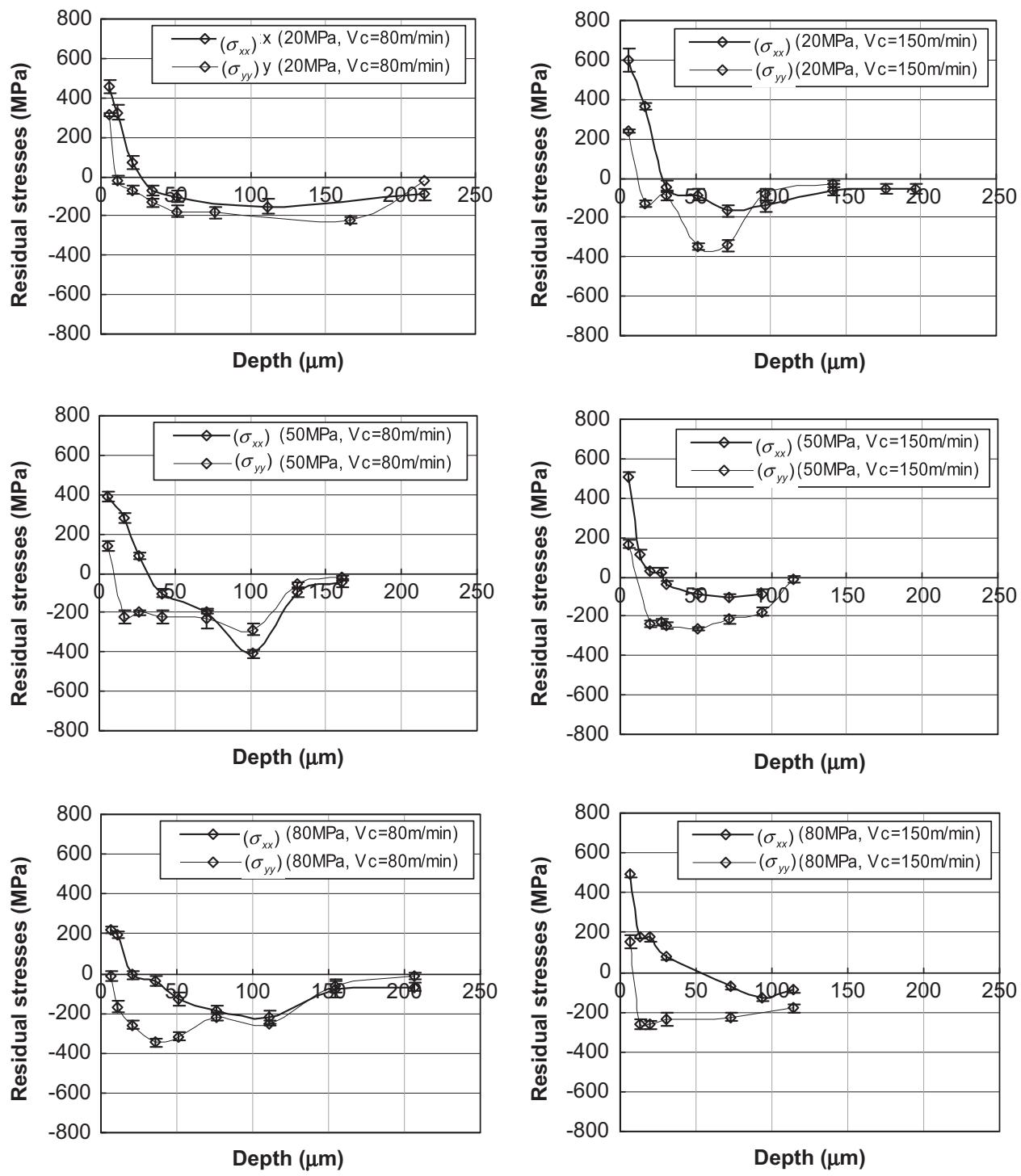

Fig. 9. Longitudinal residual stresses profiles obtained using HPWJAT $\left(f=0.1 \mathrm{~mm} / \mathrm{rev}\right.$ and $\left.a_{\mathrm{p}}=1 \mathrm{~mm}\right)$.

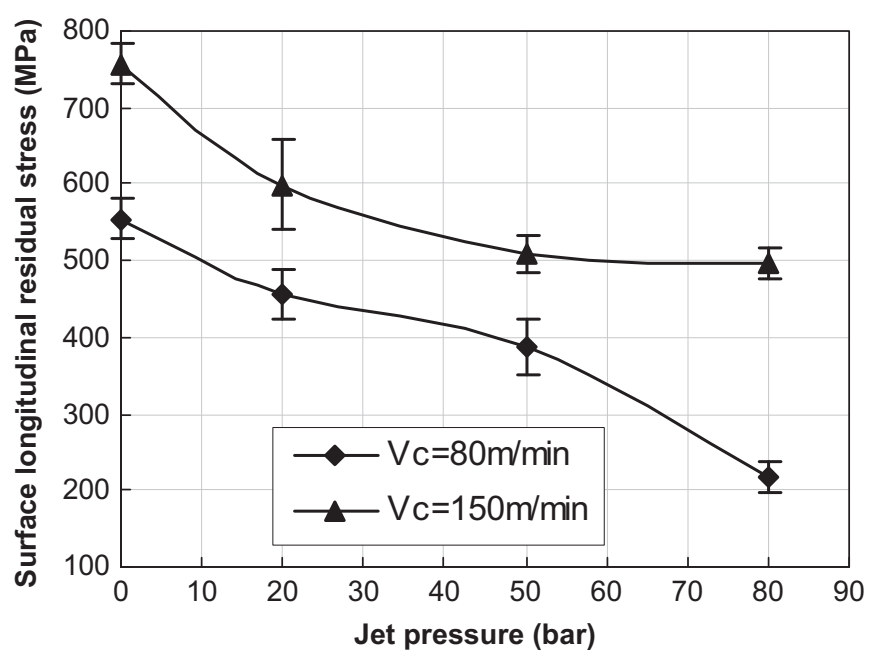

Fig. 10. Evolution of the surface longitudinal residual stresses in function of jet pressure $\left(f=0.1 \mathrm{~mm} / \mathrm{rev}\right.$ and $\left.a_{\mathrm{p}}=1 \mathrm{~mm}\right)$.
Table 3

Results of surface residual stress and values of zone $A_{1}$ obtained for different tests.

\begin{tabular}{lllll}
\hline & $\begin{array}{l}\text { Dry } \\
\text { turning }\end{array}$ & $\begin{array}{l}\text { HPWJAT } \\
(20 \mathrm{MPa})\end{array}$ & $\begin{array}{l}\text { HPWJAT } \\
(50 \mathrm{MPa})\end{array}$ & $\begin{array}{l}\text { HPWJAT } \\
(80 \mathrm{MPa})\end{array}$ \\
\hline $\begin{array}{l}V_{\mathrm{c}}=80 \mathrm{~m} / \mathrm{min}, f=0.1 \mathrm{~mm} / \mathrm{rev} \text { and } \\
\text { External stress, } \sigma_{x x}=1 \mathrm{~mm} \\
(\mathrm{MPa})\end{array}$ & $555 \pm 30$ & $455 \pm 30$ & $390 \pm 40$ & $220 \pm 15$ \\
$\begin{array}{l}A_{1}(\mu \mathrm{m}) \\
V_{\mathrm{c}}=150 \mathrm{~m} / \mathrm{min}, f=0.1 \mathrm{~mm} / \mathrm{rev} \text { and } a_{\mathrm{p}}=1 \mathrm{~mm} \\
\begin{array}{l}\text { External stress, } \sigma_{x x} \\
(\mathrm{MPa})\end{array}\end{array}$ & $760 \pm 25$ & $600 \pm 60$ & $50 \pm 25$ & $495 \pm 20$ \\
$A_{1}(\mu \mathrm{m})$ & 25 & 30 & 30 & 50 \\
\hline
\end{tabular}

hardening in turning. Indeed, the width of the diffraction peaks is directly related to the crystallite size and lattice distortion. In a high plasticity deformed material (work hardening), the effect of the lattice distortion due to dislocations is higher than the size effect, which in the X-ray diffraction analysis cannot be properly quantified except by material without work hardening and with 
crystallite size inferior to $0.2 \mu \mathrm{m}$. In this study, the size effect is negligible compared to the material work hardening.

The depth profiles of the mean X-ray diffraction peak obtained in dry turning and HPWJAT at two cutting speeds and different jet pressures are investigated in this section.

\subsubsection{Dry turning}

The mean X-ray diffraction peak width profiles within the depth of the workpiece obtained at cutting speeds of $80 \mathrm{~m} / \mathrm{min}$ and $150 \mathrm{~mm} / \mathrm{rev}$, using dry turning, are illustrated in Fig. 11a and b. This figure shows that the mean X-ray diffraction peak width curves are similar.

As shown in Fig. 11a the zone representing the depth affected by hardening $\left(A_{2}\right)$ is defined.

\subsubsection{High-pressure jet assisted turning}

Fig. 12 presents the mean X-ray diffraction peak width profiles within the depth of the workpiece obtained at cutting speeds of $80 \mathrm{~m} / \mathrm{min}$ and $150 \mathrm{~mm} / \mathrm{rev}$ in HPWJAT for different jet pressures (20, 50 and $80 \mathrm{MPa}$ ). It was observed that for all cases the same evolution of mean X-ray diffraction peak width within depth can be observed.

3.3.3. Discussion of the mean X-ray diffraction peak width evolution For all the results, it was observed that the tensile stresses are associated with strong work hardening in the workpiece surface layer. The maximum mean X-ray diffraction peak width value is greater than $3^{\circ}$. The values decrease continuously with the depth and then stabilised at $1.5^{\circ}$ corresponding to the initial material state.

The maximum mean X-ray diffraction peak width value is greater than $3^{\circ}$, which shows the work hardening state at the surface. Compared to the material before machining, a significant hardening on the surface after turning was observed. The influence of the jet pressure on the mean X-ray diffraction peak width at the surface of the workpiece is very strong as can be deduced from Fig. 13 and Table 4. On the surface, work hardening decreases strongly with an increase in jet pressure.

The level of surface mean X-ray diffraction peak width obtained using dry turning at $V_{\mathrm{c}}=150 \mathrm{~m} / \mathrm{min}$ and that obtained using HPWJAT at the same cutting parameters and $P=80 \mathrm{MPa}$ are $3.5^{\circ}$ and $2.9^{\circ}$, respectively. Also, the depth $A_{2}$ affected by hardening varies from 60 to $80 \mu \mathrm{m}$ (at $V_{\mathrm{c}}=150 \mathrm{~m} / \mathrm{min}$ ). Hence, it can be concluded that high jet pressure does not greatly influence the depth of zone $A_{2}$ as can be seen in Table 4. On the other hand, the

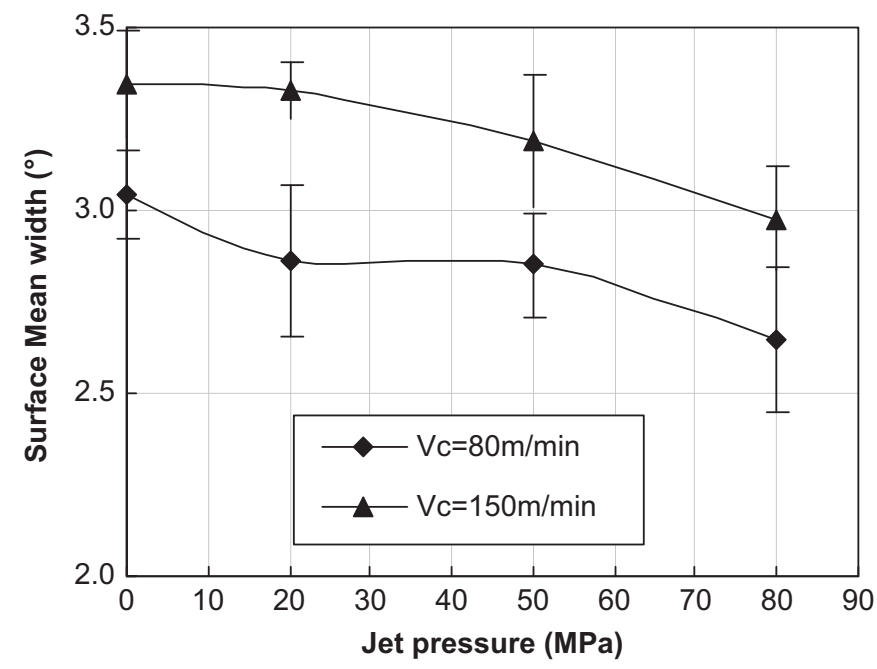

Fig. 13. Evolution of the surface mean $\mathrm{X}$-ray diffraction peak width as a function of the jet pressure ( $V_{\mathrm{c}}=80$ and $150 \mathrm{~m} / \mathrm{min}, f=0.1 \mathrm{~mm} / \mathrm{rev}$ and $a_{\mathrm{p}}=1 \mathrm{~mm}$ ).
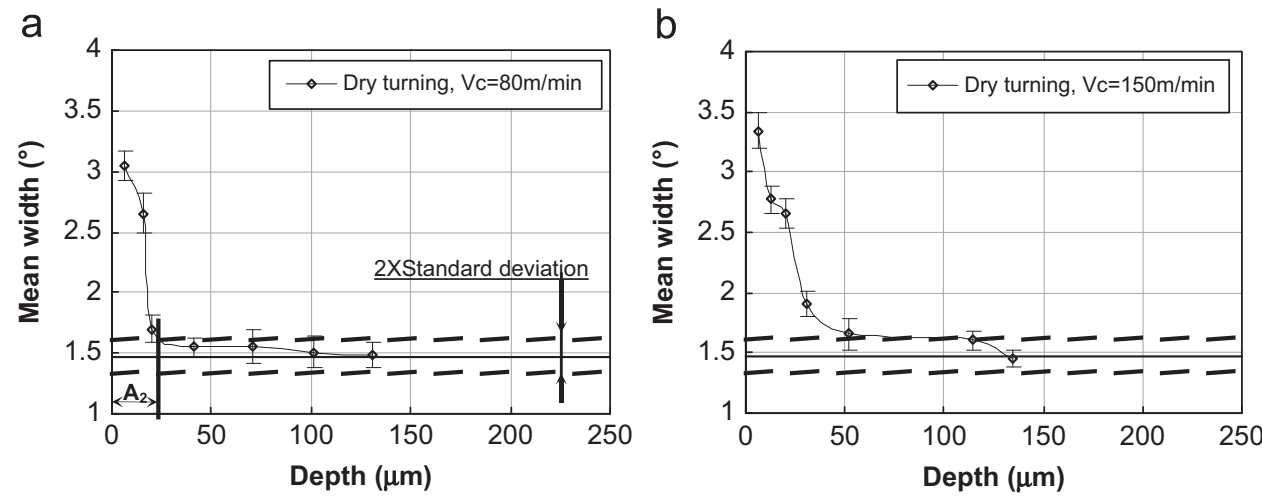

Fig. 11. Mean X-ray diffraction peak width profiles obtained by dry turning: (a) $V_{\mathrm{c}}=80 \mathrm{~m} / \mathrm{min}$ and (b) $V_{\mathrm{c}}=150 \mathrm{~m} / \mathrm{min}$.
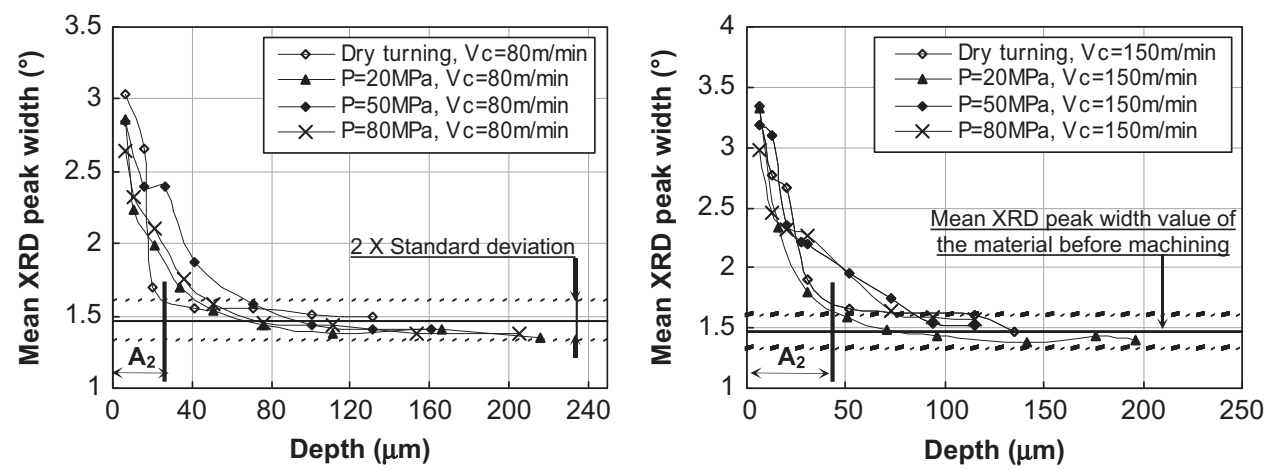

Fig. 12. Mean X-ray diffraction peak width profiles obtained by using dry and HPWJAT $\left(f=0.1 \mathrm{~mm} / \mathrm{rev}\right.$ and $\left.a_{\mathrm{p}}=1 \mathrm{~mm}\right)$. 
Results of mean XRD peak width and values of $A_{2}$ obtained for different tests.

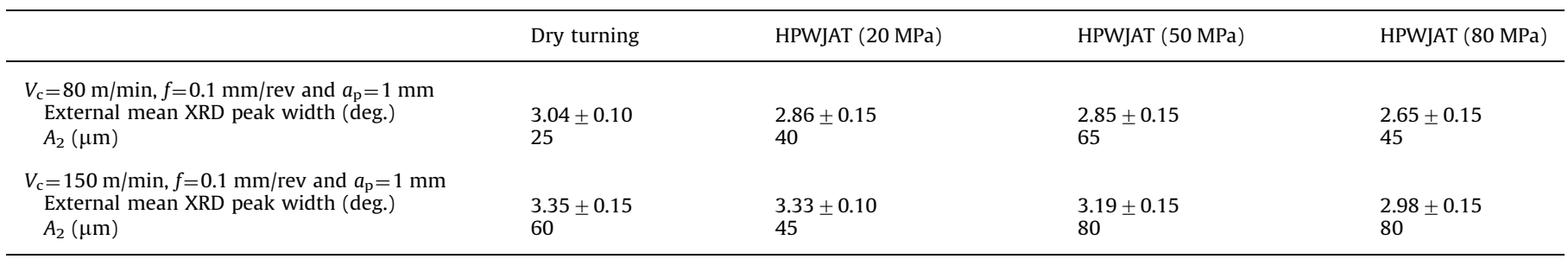

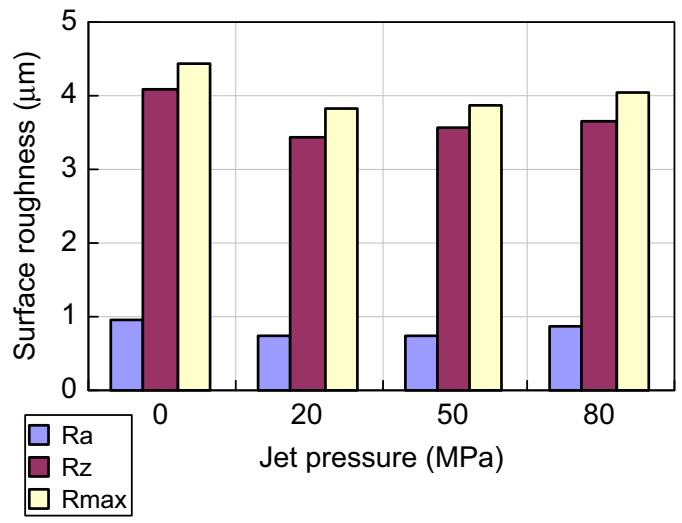

Fig. 14. Variation in surface roughness of $316 \mathrm{~L}$ material machined in dry turning and using HPWJAT at cutting speed of $150 \mathrm{~m} / \mathrm{min}$ and feed rate of $0.1 \mathrm{~mm} / \mathrm{rev}$.

mean X-ray diffraction peak width follows the cutting speed variation on the surface.

\subsection{Surface roughness and tool wear}

\subsubsection{Surface roughness}

For a description of the surface quality after turning, it is common to select the surface roughness. For all tests, the roughness of the machined surface has been analysed through the $R_{\mathrm{a}}$ (arithmetic average), $R_{\mathrm{z}}$ and the $R_{\max }$ factors. Fig. 14 shows different values of the surface roughness obtained in the case of dry and HPWJA turning at the cutting speed of $150 \mathrm{~m} / \mathrm{min}$ and a feed rate of $0.1 \mathrm{~mm} / \mathrm{rev}$. It was observed that the introduction of the high jet pressure does not significantly influence the surface roughness values. Thus the value of the $R_{\mathrm{a}}$ was seen to vary from $0.95 \mu \mathrm{m}$ in the case of dry turning to $0.85 \mu \mathrm{m}$ using HPWJAT at $80 \mathrm{MPa}$.

The study of the effect of jet pressure on the surface roughness has been carried out for different jet pressures $(20,50$ and $80 \mathrm{MPa}$ ). It was observed that when the jet pressure is increased from 20 to $80 \mathrm{MPa}$, the surface roughness values tend to decrease but this variation does not pronounce (see Fig. 14). About these results, it can be concluded that the HPWJAT does not modify significantly the surface roughness values.

The surface roughness is mainly associated to the feed rate and the cutting tool geometry (in this study, the feed rate is constant $a_{\mathrm{p}}=0.1 \mathrm{~mm} / \mathrm{rev}$ ); on contrary the residual stresses are principally associated to the cutting forces and the heat gradients on the machined extreme surface workpiece. The high pressure assistance comes mainly to

- apply a mechanical action on the chip, thus inducing its fragmentation;

- reduce the cutting forces [18] and contribute to decrease the tool-workpiece friction and the heat gradient induced by the cutting operation, which represents a direct consequence of the residual stresses on the extreme surface and

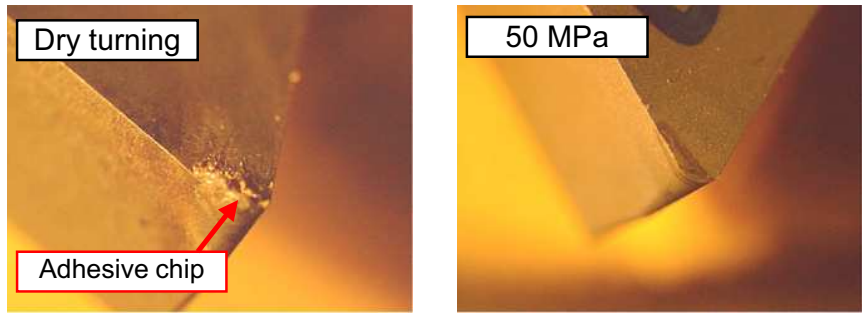

Fig. 15. Worn out insert after one machining test in dry and $\operatorname{HPWJAT}\left(V_{\mathrm{c}}=150 \mathrm{~m} / \mathrm{min}\right.$, $f=0.1 \mathrm{~mm} / \mathrm{rev}$ and $a_{\mathrm{p}}=1 \mathrm{~mm}$ ).

- decrease the tool wear, which has a light effect on the surface roughness compared to the influence on the cutting forces and the cutting heat.

After turning, the worn out of the insert was examined (see Fig. 15). In the case of dry turning at the cutting speed of $150 \mathrm{~m} / \mathrm{min}$ and feed rate of $0.1 \mathrm{~mm} / \mathrm{rev}$, abrasive scratch marks appeared on the flank with the presence of adhesive chip. There have been some indications of tool degradation. For the same parameters when using HPWJAT, less degradation was observed on the rake face of the tool and there is no presence of adhesive chip. In this study, the results show that using a high-pressure jet directed into the tool-chip interface, it is clearly possible to eliminate the adhesive chip, which has a tendency to improve the tool life.

\section{Conclusions}

This paper has presented the influence of a high-pressure water jet directed into the tool-chip interface on residual stress and chip breakage shapes for face turning of AISI 316L austenitic stainless steels using a standard tool.

Contrary to a great number of previous studies relating to machining, this work is original in the sense that we look at the turning of austenitic stainless steel with a tool not meant for the machining of this steel, using High-Pressure Water Jet Assisted Turning. The aim is to obtain a bad machining (which produces a long chip and tensile residual stresses) and to improve it. The high-pressure jet is directed with precision so as to act as hydraulic corners, which tend to fragment a chip.

We concluded that

- the introduction of a high-pressure water jet into the tool-chip interface is a very satisfactory method for machining this material and

- the jet parameters have a strong influence on the surface residual stresses and chip shapes.

The experimental results show that using a high-pressure jet directed into the tool-chip interface, it is possible to create good chips and to control the chip fragmentation shapes, compared to dry turning. Fragmentation becomes possible with a tool not 
meant for machining the austenitic stainless steel. It is concluded that the surface residual stresses can be reduced by introduction of a high-pressure water jet. A reduction in the surface longitudinal residual stresses $\sigma_{x x}$ value (highly tensile) by about $20-40 \%$ was observed when using HPWJAT compared to dry turning. In terms of surface roughness it was observed that the HPWJAT does not greatly influence the surface roughness values but it is possible to decrease the tool wear. Also, it has been observed that the jet pressure has little influence on the depths affected by tensile residual stress and by hardening.

The HPWJAT can be a solution at the problems of materials machining, like Inconel, titanium or austenitic stainless steel, which tend to work hardening during the cutting operation and to form long chips favourable to deteriorate the machined surface and cutting tool.

\section{Acknowledgements}

The authors would like to thank P. Robert and C. Fischer of the ENSAM France and S. Waldmann of the Institut für Werkstofftechnik in Germany for their assistance during this work and RIVARD Company for its technical supports (high-pressure group).

\section{References}

[1] R. M'Saoubi, J.C. Outeiro, B. Changeux, J.-L. Lebrun, Morao Dias, Residual stress analysis in orthogonal machining of standard and resulfurized AISI 316L steels, Journal of Materials Processing Technology 96 (1999) 225-233.

[2] E. Capello, Residual stresses in turning, part I. Influence of process parameters, Journal of Materials Processing Technology 160 (2005) 221-228.

[3] J. Rech, A. Moisan, Surface integrity in finish hard turning of case-hardened steels, International Journal of Machine Tools \& Manufacture 43 (2003) 543-550.

[4] M. Jacobson, P. Dahlman, F. Gunnberg, Cutting speed influence on surface integrity of hard turned bainite steel, Journal of Materials. Processing Technology 128 (2002) 318-323.

[5] P. Dahlman, F. Gunnberg, M. Jacobson, The influence of rake angle, cutting feed and cutting depth on residual stresses in hard turning, Journal of Materials Processing Technology 147 (2004) 181-184.
[6] Dale W. Schwach, Y.B. Guo, Feasibility of producing optimal surface integrity by process design in hard turning, Materials Science and Engineering A 395 (2005) 116-123.

[7] M. Habak, Etude de l'influence de la microstructure et des paramètres de coupe sur le comportement en tournage dur de l'acier à roulement $100 \mathrm{Cr} 6$, Thèse ENSAM, 2006, n 2006 ENAM 57.

[8] M. Habak, J.-L. Lebrun, D. Bellet, C. Fischer, The Effect of Carbides, Material Hardness and Cutting Parameters on Residual Stresses Generated by the Hard Turning of 100Cr6 (AISI 52100), ESAFORM, 2006, pp. 615-618.

[9] C. Wiesner, Residual Stress after orthogonal machining of AISI 304: numerical calculation of the thermal component and comparison with experimental results, Metallurgical and Materials Transactions A23 (1989) 989-996.

[10] R. M'Saoubi, Aspects thermiques et microstructuraux de la coupe, Application à la coupe orthogonale des aciers austénitiques, Thèse de Mécanique et Matériaux, ENSAM Paris, 1998, n $1998-09$.

[11] R. Komanduri, T. Schroeder, B.F. Von Turkovitch, O.G. Flom, On the catastrophic shear instability in high speed machining of an AISI 4340 steel, Transactions of the ASME Journal of Engineering for Industry 104 (1982) 121-131.

[12] G. Poulachon, Aspects phénoménologiquement, mécaniques et métallurgiques en tournage c-BN des aciers durcis, Thèse, 1999, Cluny, France.

[13] G. Poulachon, A.L. Moison, M. Dessoly, A contribution to the study of the cutting mechanisms in hard turning, Mécanique \& Industries 3 (2002) 291-299.

[14] M. Habak, C. Fischer, J.-L. Lebrun, Rôle de l'assistance jet d'eau haute pression sur les contraintes résiduelles de pièces en acier inoxydable austénitique usiné, Journée du Groupement Français d'Analyse des Contraintes/SF2M, ENSAM Aix en Provence, 22-23 avril 2004.

[15] P. Dahlman, M. Escursell, High-pressure jet-assisted cooling: a new possibility for near net shape turning of decarburized steel, International Journal of Machine Tools and Manufacture 44 (2004) 10-115.

[16] R.F. Avila, A.M. Abrao, The effect of cutting fluids on the machining of hardened AISI 4340 steel, Journal of Materials Processing Technology 119 (2001) 21-26.

[17] J.M. Viera, A.R. Machado, E.O. Ezugwu, Performance of cutting fluids during face milling of steels, Journal of Materials Processing Technology 116 (2001) 244-251.

[18] R. Kovaçevic, C. Cherukuthota, M. Mazurkiewicz, High pressure water jet cooling/lubrication to improve machining efficiency in milling, International Journal of Machine Tools and Manufacture 35 (10) (1995) 1459-1473.

[19] J. Kaminski, B. Alvelid, Temperature reduction in the cutting zone in waterjet assisted turning, Journal of Materials Processing Technology 106 (2000) 68-73.

[20] C. Shet, X. Deng, A.E. Bayoumi, Finite element simulation of high-pressure water-jet assisted metal cutting, International Journal of Mechanical Sciences 45 (2003) 1201-1228.

[21] K. Okushima, Y. Kakino, A study on the residual stress produced by metal cutting, Memoirs of the Faculty of Engineering, Kyoto 34 (1972) 234-248. 